University of Nebraska - Lincoln

DigitalCommons@University of Nebraska - Lincoln

Faculty Publications from the Harold W. Manter Laboratory of Parasitology

\title{
Trematode-Gastropod Associations in Nine Non-Lacustrine Habitats in the Mwanza Region of Tanzania
}

\author{
Sam Loker \\ University of New Mexico, esloker@unm.edu \\ H. G. Moyo \\ Mwanza, Tanzania \\ Scott Lyell Gardner \\ University of Nebraska - Lincoln, slg@unl.edu
}

Follow this and additional works at: https://digitalcommons.unl.edu/parasitologyfacpubs

Part of the Parasitology Commons

Loker, Sam; Moyo, H. G.; and Gardner, Scott Lyell, "Trematode-Gastropod Associations in Nine NonLacustrine Habitats in the Mwanza Region of Tanzania" (1981). Faculty Publications from the Harold W. Manter Laboratory of Parasitology. 58.

https://digitalcommons.unl.edu/parasitologyfacpubs/58

This Article is brought to you for free and open access by the Parasitology, Harold W. Manter Laboratory of at DigitalCommons@University of Nebraska - Lincoln. It has been accepted for inclusion in Faculty Publications from the Harold W. Manter Laboratory of Parasitology by an authorized administrator of DigitalCommons@University of Nebraska - Lincoln. 


\title{
Trematode-gastropod associations in nine non-lacustrine habitats in the Mwanza region of Tanzania
}

\author{
E. S. LOKER ${ }^{1}$, H. G. MOY $\mathrm{O}^{2}$ and S. L. GARDNER \\ ${ }^{1}$ Department of Zoology, Oregon State University, Corvallis, Oregon 97331 \\ ${ }^{2}$ Institute for Medical Research, P.O. Box 1462, Mwanza, Tanzania
}

(Accepted 6 February 1981)

\begin{abstract}
S U M M A R Y
Between August 1978 and July 1979, freshwater gastropods were collected at monthly intervals from 9 different non-lacustrine habitats in the Mwanza region of Tanzania. Of a total of 11708 gastropods representing 14 species, $1748(14.9 \%)$ were infected with trematode sporocysts and/or rediae. Altogether 38 morphologically distinguishable 'species' of cercariae were recovered (13 furcocercous, 10 xiphidiocercaria, 6 echinostome, 4 cystophorous, 3 gymnocephalous and 2 amphistome species), 22 of which did not conform to previously described African species. The majority $(63.8 \%)$ of all mature infections were xiphidiocercariae. Biomphalaria pfeifferi, B. sudanica and Ceratophallus natalensis each yielded 11 species of cercariae. Lymnaea natalensis had the highest overall prevalence of infection $(36.9 \%)$. Cercaria guttera from $L$. natalensis accounted for $20.4 \%$ of all recovered trematode infections and C. blukwa from Biomphalaria accounted for $18.4 \%$ of all infections; the high prevalence of these two xiphidiocercariae may alter the transmission patterns of Fasciola gigantica and Schistosoma mansoni, respectively. S. mansoni was recovered from both $B$. sudanica (22 of 2393 infected) and $B$. pfeifferi (79 of 1913 infected); $S$. haematobium (or related species) was recovered from Bulinus (Physopsis) nasutus (50 of 1503 infected) and to a lesser extent from $B$. (P.) africanus (6 of 186 infected). The findings are discussed in relation to the biological control of trematode diseases in Tanzania.
\end{abstract}

INT RODUCTION

Numerous surveys to ascertain the prevalence of Schistosoma mansoni (Webbe, 1962a; Teesdale, 1962; Prentice, Panesar \& Coles, 1970; Magendantz, 1972) and Schistosoma haematobium (Webbe \& Msangi, 1958; Maclean, Webbe \& Msangi, 1958; Webbe, 1962b; Kinoti, $1964 a$; McCullough, Eyakuze, Msinde \& Nditi, 1968; Baalawy \& Moyo, 1970) in populations of their snail intermediate hosts have been undertaken in East Africa. Likewise, some attention has been given to the prevalence of bovine schistosomes in Bulinus (Physopsis) ugandae (Berrie, 1964) and of Fasciola gigantica in populations of Lymnaea natalensis (Ogambo-Ongoma, 1971) from Uganda, but relatively little information on the abundance, morphology and host relationships of other East African trematode species not of medical or veterinary importance has accumulated. 
Further documentation of the larval trematode fauna is important not only for its own sake, but also to provide a more realistic understanding of the ecological setting in which schistosomiasis, fascioliasis and other snail-borne diseases occur. For instance, as reported by Chu, Dawood \& Nabi (1972), under certain circumstances the prevalence of $S$. haematobium infections in Bulinus truncatus in the Nile Delta may be reduced by antagonistic larval echinostomes naturally present in this endemic area. In the Gezira irrigation system of Sudan, larval echinostomes have also been noted to be abundant in local $B$. truncatus populations, a factor which may to some extent be responsible for the uneven distribution and low prevalence of $S$. haematobium in this region (Amin, personal communication cited by McCullough, 1981).

Also, study of the trematode fauna in endemic areas may reveal the existence of certain species that could be manipulated to achieve biological control of snail-transmitted diseases. Field experiments in Thailand by Lie, Kwo \& Owyang (1971) and Lie, Schneider, Sornmani, Lanza \& Impand (1974) have shown that in some cases Schistosoma spindale infections in Indoplanorbis exustus can be reduced or eliminated in natural ponds by introduction of large numbers of eggs of carefully selected antagonistic species originating from the same geographic area.

Finally, knowledge of the trematode fauna present is important because high levels of trematode infections may in some cases be responsible for eliminating certain snail populations. In an extensive study of the biology of cercariae from Danish freshwaters, Wesenberg-Lund (1934) frequently observed that if a snail population had been highly infected with trematodes, the population often totally disappeared by the following year. In a variety of Ugandan freshwater habitats, Cridland $(1957 a, b, 1958)$ often noted an intriguing correlation between the prevalence of larval trematode infections and the reduction in size of snail populations, and he postulated that parasitism was responsible for the observed declines. Morris (1970) has concluded that the irregular distribution of the planorbid snail Helisoma trivolvis in ponds of central Alberta may be a consequence of the repeated introduction of the trematode Echinoparyphium recurvatum into these habitats; such introductions eventually resulted in excessive juvenile snail mortality and castration of adult snails which in turn led to snail population crashes and in some cases, extinction. Lie et al. $(1971,1974)$ have reported that after artificially inducing very high echinostome infection rates in a natural population of 1 . exustus, the host population declined significantly due to the adverse effects on host reproduction and survivorship of the trematodes. In Guadeloupe, eggs of Ribeiroia marini guadeloupensis, a cathaemasiid trematode capable of parasitically castrating Biomphalaria glabrata, were introduced over a 15-month period into a pond containing a population of this snail host; almost all the snails had disappeared by the end of the trial (Nassi, Pointier \& Golvan, 1979).

This study was undertaken as a preliminary step to define the digenetic trematode fauna in a geographic area in which a number of snail-borne diseases are endemic. It is hoped that this investigation will provide useful background information on future studies of the biological control of these diseases. 


\section{DESCRIPTION OF THE MWANZA REGION}

Five of the 9 habitats sampled at monthly intervals were located in Mwanza, a rapidly expanding city situated on the south shore of Lake Victoria. Two habitats were located between Mwanza and Misungwi, the latter a village situated $46 \mathrm{~km}$ south of Mwanza on the road to Tabora. The remaining two habitats were located near Misungwi. The geology and climate of this portion of Tanzania are described by Webbe (1962b) and McCullough, Webbe, Baalawy \& Maselle (1972). Briefly, the area lies at an altitude of 1020-1220 $\mathrm{m}$ above sea level and consists of rolling plains interspersed with low rugged granite outcrops and hills. Rainfall is usually 700-1000 mm per year, most of which falls from mid-November to May, often with a brief intermission in January or February. March and April are frequently the wettest months and are followed by a long dry season which extends from May to October. In general, the rainfall for Mwanza and Misungwi during the present study conformed to the expected seasonal patterns (Table 3). Aquatic snail habitats abound in this area, particularly during the rainy season, and include Lake Victoria and its backwaters, streams, large and small impoundments, seepage areas, temporary pools, rice paddies and irrigation ditches in small gardens.

$S$. mansoni is particularly widespread in urban Mwanza and is transmitted in Lake Victoria by Biomphalaria choanomphala, around the lake margins and in streams by Biomphalaria sudanica, and elsewhere in the region by Biomphalaria pfeifferi (Webbe, 1962a; Magendantz, 1972; McCullough et al. 1972). S. haematobium is also endemic and is transmitted primarily in rural areas, in temporary pools and manmade habitats where Bulinus (Physopsis) nasutus is the principal intermediate host (Webbe, 1962b; MeCullough et al. 1968). Bulinus (Physopsis) africanus is also known to transmit urinary schistosomiasis in streams (Kinoti, $1964 a$ ). Trematodes of domestic ruminants include Schistosoma mattheei and Schistosoma bovis (Dinnik \& Dinnik, 1965), F. gigantica and paramphistomes.

\section{Habitats sampled}

Snails were collected with dip nets at monthly intervals (August 1978 to July 1979) from the 9 habitats indicated below. Although sampling was usually restricted to 1.5 man-hours/habitat/month, the snail collections should not be regarded as quantitative monthly determinations of relative snail population density. Attempts were made to ensure that the relative abundance of different species and size categories of snails in our collections accurately reflected the situation in the habitat, that is, we did not preferentially collect particular size classes of snails. Usually 100-200 snails were collected from each habitat each month. A description of the 9 habitats is given below.

(A) Small shallow pool located in the Bwiru section of Mwanza, separated from Pasiansi Bay of Lake Victoria by a narrow strip of sandy beach. Human activity along this sandy beach was extensive although little direct use of the water in the pool by either humans or domestic animals was observed.

(B) Series of parallel irrigation ditches located in the Kigoto section of Mwanza. These ditches were orientated perpendicular to the shore of North Mwanza Bay of Lake Victoria and the water in this habitat was confluent with that of the lake. 
A portion of this habitat flooded when the lake level rose in February 1979. Women and children made extensive use of the lakeshore adjacent to this habitat.

(C) Kirumba Stream, adjacent to Airport Road in Mwanza. The course of this small, intermittent stream was frequently altered by human activity. Heavy rainfall occasionally made collection at this habitat difficult. Many houses were located around this stream.

(D) Kitangiri Stream, adjacent to the new football stadium in Mwanza. This 'stream' actually consisted of shallow, interconnected grass-choked pools; water flow through this habitat was minimal. This habitat was immediately surrounded by rice fields and children were often seen playing near the stream.

(E) Nyakabungo Stream, adjacent to Mirongo School in Mwanza. This gentleflowing stream consisted of several shallow, interconnected pools containing dense emergent vegetation. Children from the school were frequently observed playing in and around this stream.

(F) Spring-fed seepage area situated $21.6 \mathrm{~km}$ south of Mwanza on the road to Misungwi, in an area known as Nyahomongo. This series of small pools contained very little water and few snails during the first 4 months of this study, but they later expanded as the rainy season commenced and snails became abundant.

(G) Temporary, rain-fed pool situated $33.9 \mathrm{~km}$ south of Mwanza along the road leading to Misungwi, in an area known as Ngombe. This turbid pool contained little water during August and September and was completely dry in October and November. By January it had filled with rain and supported dense snail populations. Little emergent vegetation was evident in this habitat.

(H) Misungwi Stream, $0.5 \mathrm{~km}$ east of Misungwi. This intermittent stream consisted of a series of deep interconnected pools. It was not observed to be flowing during the first 5 months of this study, but by April it was flowing at such a high level that collection became difficult.

(I) Spring-fed seepage area $6.4 \mathrm{~km}$ east of Misungwi in an area known as Itale. The pools comprising this habitat retained water until February when they were drained by local rice farmers. Otherwise, little human contact with this habitat was noted.

Unless otherwise indicated, the habitats retained water throughout the 12 -month study period.

\section{METHODS}

Once collected, snails were brought to the laboratory as soon as possible and were isolated in $10 \mathrm{ml}$ beakers which were placed in darkness until the following day; the beakers were then inspected at least twice for the presence of cercariae. Snails were measured to the nearest half millimetre and were eventually crushed and examined under a stereoscopic dissecting microscope for evidence of trematode infections. Snails harbouring sporocysts or rediae containing cercariae insufficiently developed to permit identification were classified as 'infected' when calculating prevalence rates. Fully developed cercariae were vital stained with nile blue sulphate and examined under the compound microscope. Additional morphological observations and measurements were made using cercariae that had been fixed in hot $10 \%(\mathrm{v} / \mathrm{v})$ formalin, subsequently stained in Mayer's paracarmine and fast 
green and mounted on microslides. Cercariae were compared with existing descriptions of African cercariae, and were classified as ' undescribed' if not closely corresponding to described species. Sufficient information on size, flame cell patterns, stylet shapes, head spine counts etc. was collected in most cases to unambiguously recognize the cercariae, but time did not permit exhaustive description of all the morphological features of each species of cercaria recovered. Slides, drawings and descriptions of the cercariae recovered in this study are available from the Experimental Taxonomy Unit, Department of Zoology, British Museum (Natural History), London.

\section{Comments on identification of the molluscan hosts}

Dr David S. Brown of the British Museum (Natural History) has examined specimens from most of the taxonomically perplexing populations of snails discussed in this paper and he has confirmed or corrected the original identifications of the authors. Correspondence with Dr Brown has raised the following points.

(1) The Biomphalaria snails recovered from habitats D and $\mathrm{H}$ were originally identified as $B$. pfeifferi by the authors but their shells show some resemblance to $B$. sudanica and conceivably, the snails from these 2 populations may be the products of hybridization. A thorough study of the morphology, biochemical properties and genetics of these and other populations would be necessary to answer satisfactorily this question. For the present, the snails from habitats $D$ and $\mathrm{H}$ are considered to be $B$. pfeifferi? and they are referred to as $B$. pfeifferi throughout this paper. Of a total of $1913 \mathrm{~B}$. pfeifferi examined for trematode infection, 1150 were from habitat $\mathrm{D}$ and 85 were from habitat $\mathrm{H}$.

(2) It must be acknowledged that at present it is very difficult to separate accurately Bulinus (Physopsis) globosus and $B$. (P.) ugandae originating from the Lake Victoria region. Bulinid snails from habitat $\mathrm{D}$ are considered to be $B$. $(P$.) globosus because their shells possess a strong columellar ridge and at least some microsculpture, and progeny of snails collected from this habitat were successfully infected with Schistosoma haematobium; of 42 snails exposed to 5 miracidia each, 9 eventually shed cercaria (Loker, unpublished observations). The bulinid snails collected from habitats $\mathrm{B}$ and $\mathrm{E}$ were designated as $B$. (P.) ugandae because their shells possessed a weak columellar ridge and poorly developed microsculpture. Much additional study of the africanus group of the genus Bulinus, including further analyses of isoelectric focusing of digestive gland enzymes (for example, Rollinson \& Southgate, 1979), is required before specific identities can be confidently assigned.

(3) The viviparid snail of the genus Bellamya which was collected from habitat $\mathrm{H}$ is considered to be Bellamya capillata on the basis of shell morphology, but examination of additional material is required before this identification can be solidly reconfirmed. 
RESULTS

From the 9 habitats sampled, a total of 11708 snails representing 5 families, 9 genera and 14 species were collected, of which $1748(14.9 \%)$ were infected with trematode sporocysts and/or rediae (Table 1). A total of 38 morphologically distinguishable 'species' of cercariae were recovered from these snails (13 furcocercous, 10 xiphidiocercariae, 6 echinostome, 4 cystophorous, 3 gymnocephalous and 2 amphistome species). The great majority $(63.8 \%$ ) of all mature infections were xiphidiocercariae. Twenty-two of the cercarial species recovered did not conform to previous descriptions (Table 2).

B. sudanica, B. pfeifferi and Ceratophallus (= Anisus) natalensis each yielded a diverse cercarial fauna (11 species); the host species with the highest overall prevalence of infection was $L$. natalensis $(36.9 \%)$. Of all trematode infections recovered in this study, $36.9 \%$ were found in $L$. natalensis.

The most common species of cercaria recovered was Cercaria guttera Fain (no. 17 of this study) from $L$. natalensis which accounted for $20.4 \%$ of all trematode infections recorded. C. blukwa Fain (no. 16) was also abundant and represented $18.4 \%$ of all recovered infections. Snails infected with sporocysts and/or rediae which contained incompletely developed cercariae were found 388 times and accounted for $22.2 \%$ of all infections. Many of these unrecognizable infections were probably either $C$. guttera or C. blukwa.

Overall prevalence in 7 of the 9 habitats ranged between 10 and $20 \%$ but was particularly high in habitat E (27.2\%) due to a large population of heavily infected $L$. natalensis, and very low at habitat $\mathrm{G}(1.0 \%)$ which supported a large population of $B$. (P.) nasutus with low infection rates. The number of cercarial species recovered from each of the 9 habitats ranged from 9 to 17 , except for habitat $G$ which yielded only 2 species. The much lower prevalence rate and diversity of cercarial species observed in habitat $G$ were undoubtedly consequences of the ephemeral nature of this habitat and the presence of a snail population composed almost entirely of a single species, $B$. (P.) nasutus.

Although considerable variation existed between snail species and habitats, the combined prevalence of infection in all habitats for all species was highest at the beginning of this study (Aug-Oct) which represented the end of the 1978 dry season (Table 3). By November, the overall prevalence rate had dropped and fluctuated throughout the rainy season and early 1979 dry season. It reached its lowest point during June but showed a sharp increase during July, the final collection month. The seasonal changes in the overall infection rate to a large extent reflect fluctuations in the relative numbers of B. pfeifferi and L. natalensis collected. These 2 snail species were relatively abundant and were considerably more likely to be infected than other species. The particularly high overall infection rate noted for the month of September was in part a consequence of the relatively large number of $B$. pfeifferi collected but nonetheless, most populations of this and other species did reveal comparatively high infection rates during this month. Of the 9 snail species for which over 500 specimens were collected, peak trematode infection rates were observed in the late dry-early rainy season for 6 of them (B. pfeifferi, $B$. sudanica, B. (B.) forskali, $B$. (P.) globosus, $B$. (P.) ugandae and Pila ovata). $C$. natalensis infection rates were highest from January to March, and $B$. ( $P$.) nasutus 


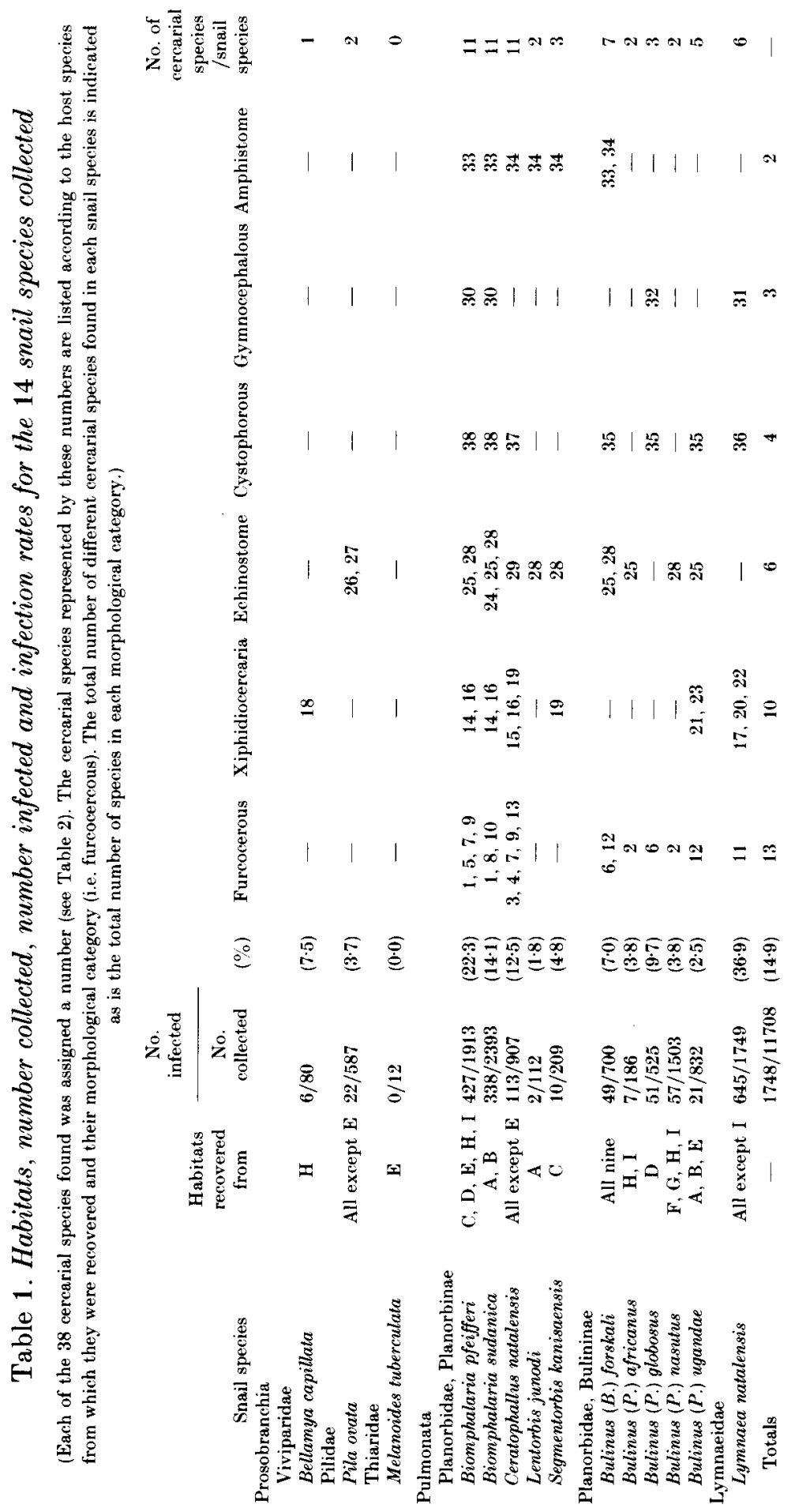



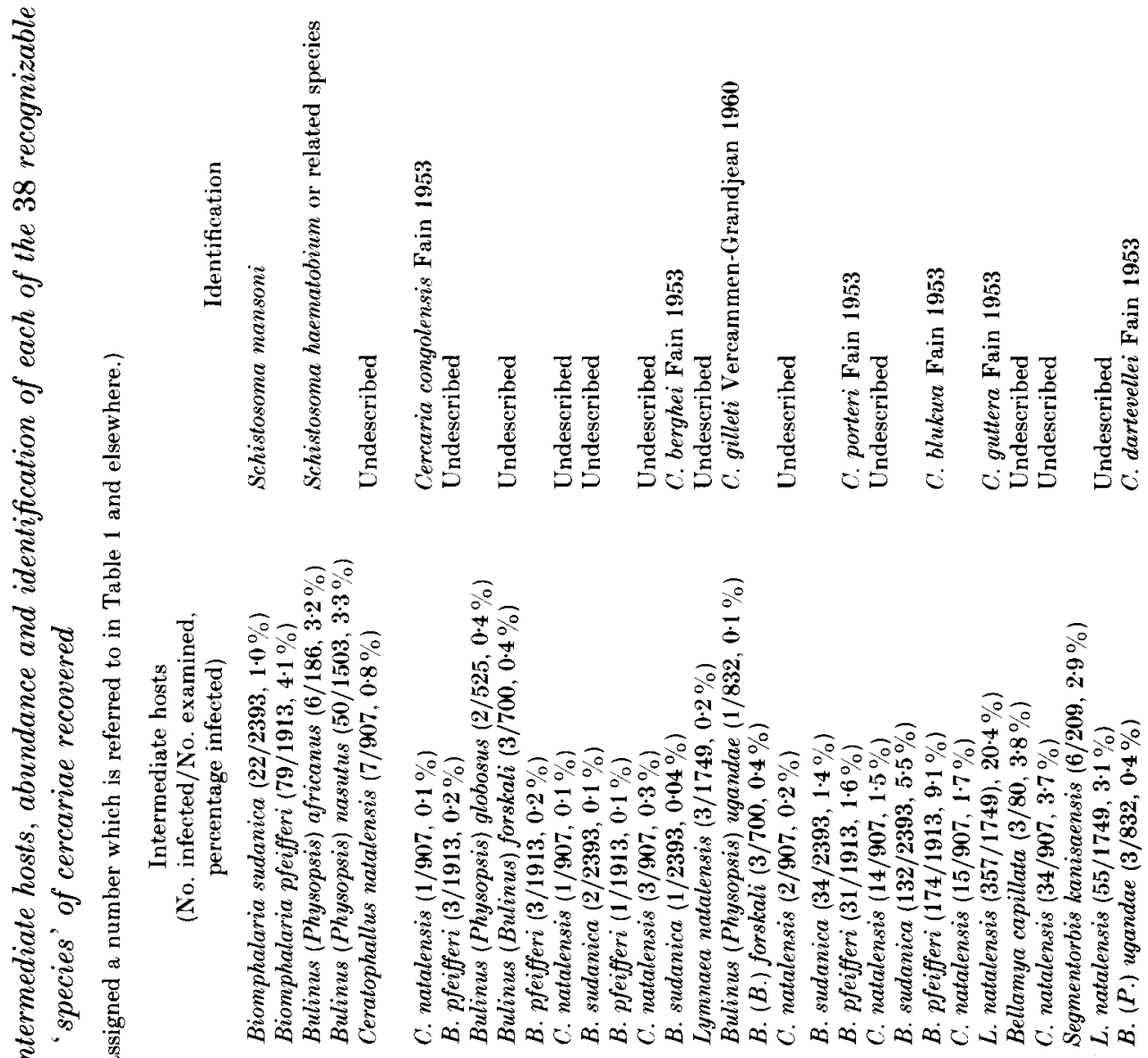

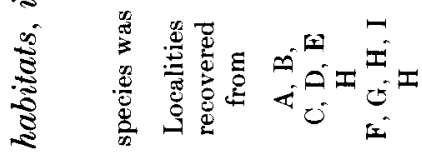

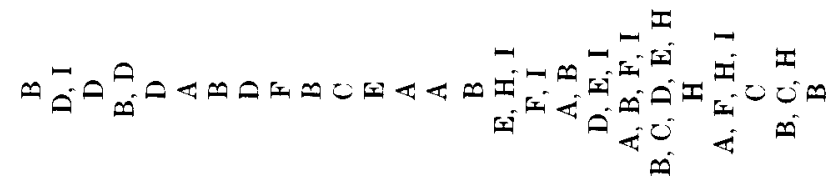

ลे.

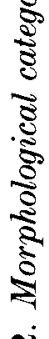
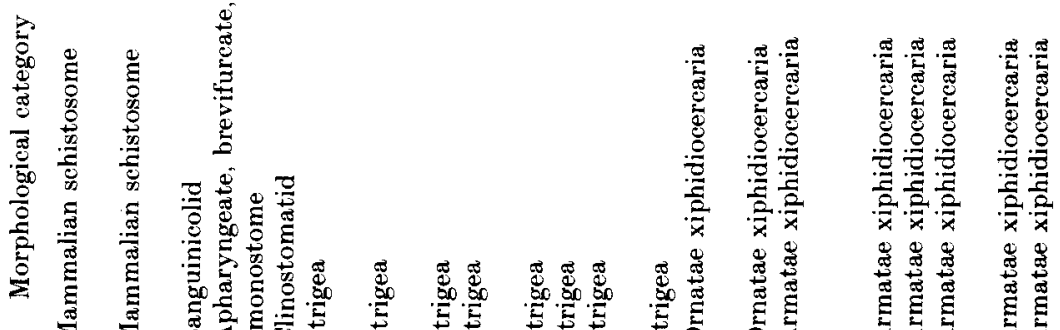

马

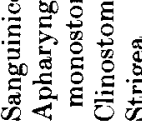

要

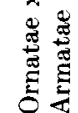

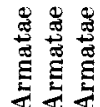

密焉富

$\frac{0}{0}$

密

$\infty \quad \varrho=\cong$

129

เ๐. ลิ 

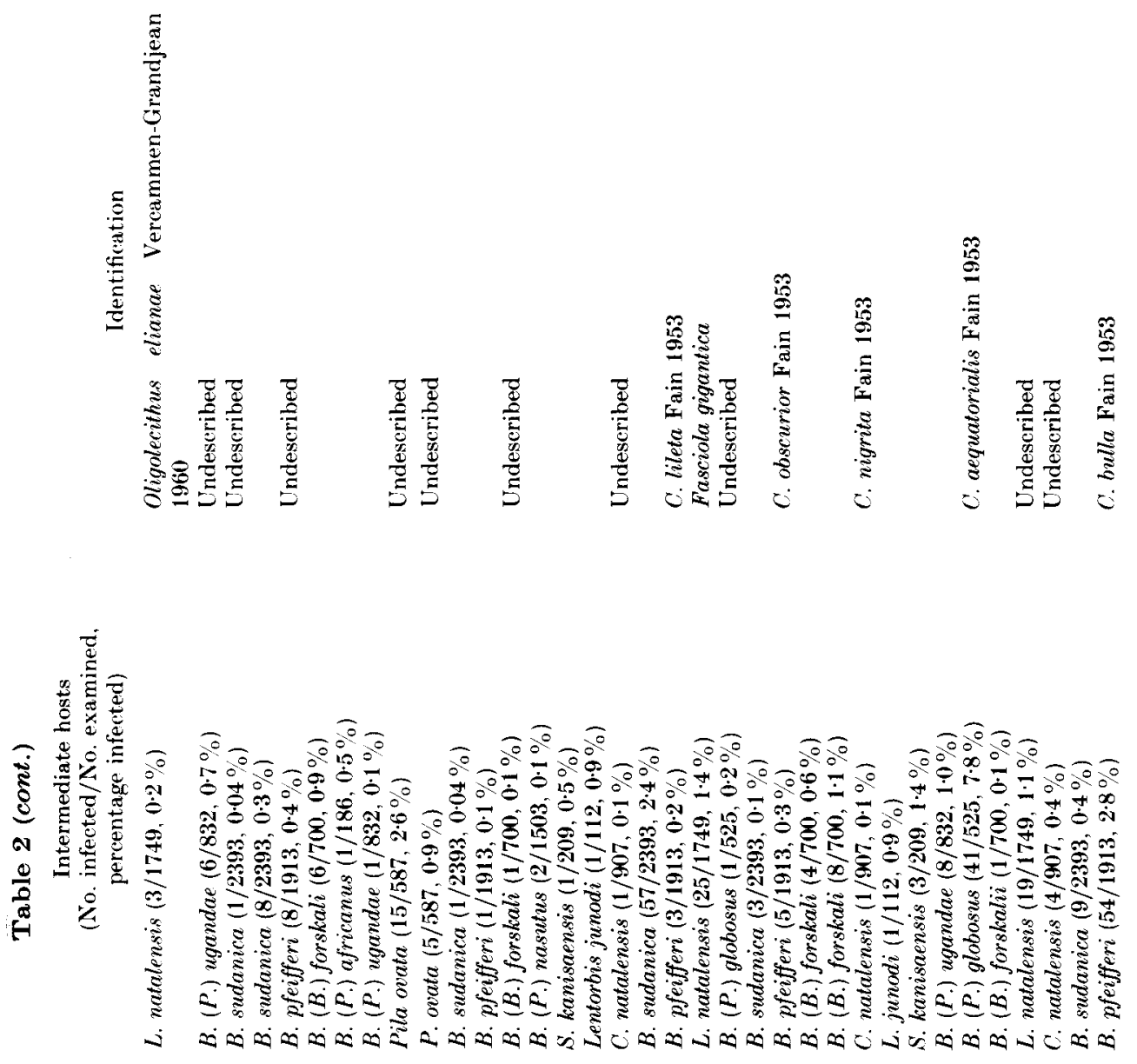

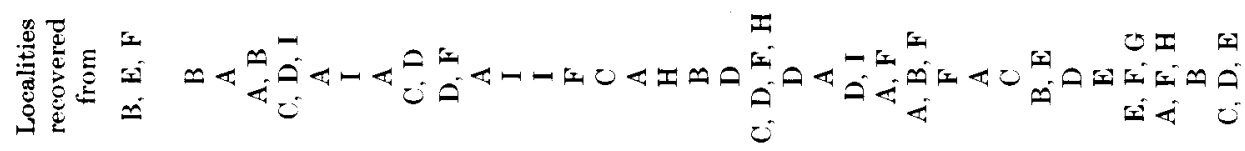

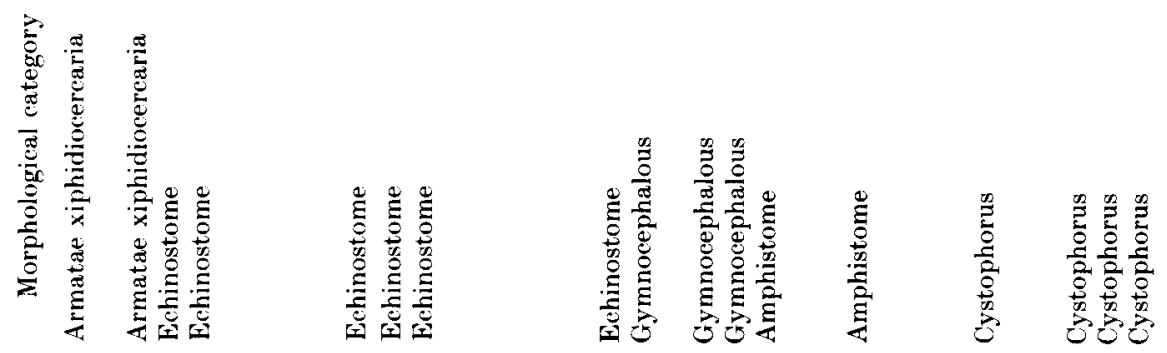

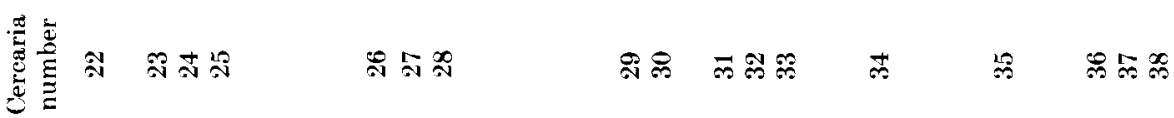


छे



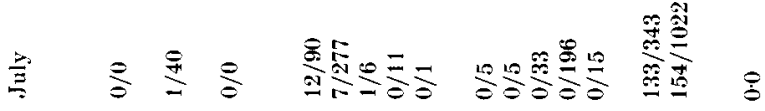

苟 吾



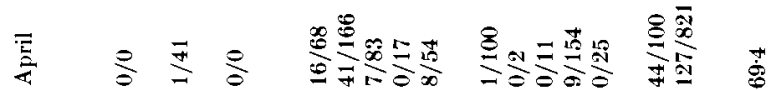

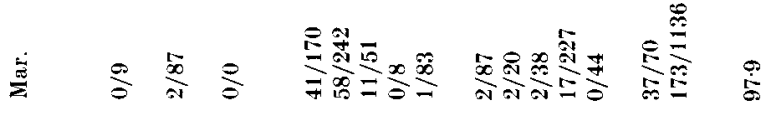

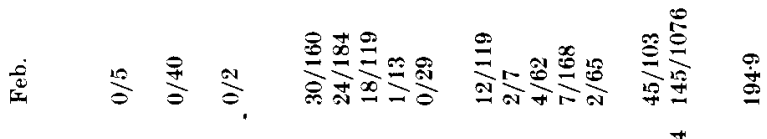



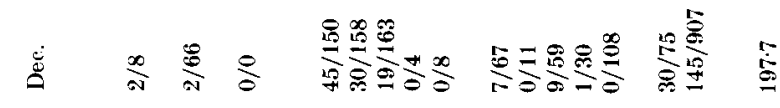

$\stackrel{2}{2}$

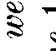

उ

蛋

¿ิ

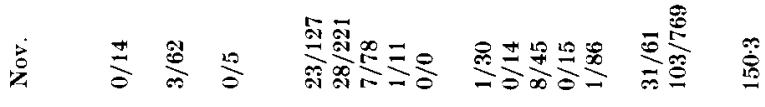

8 这

एँ

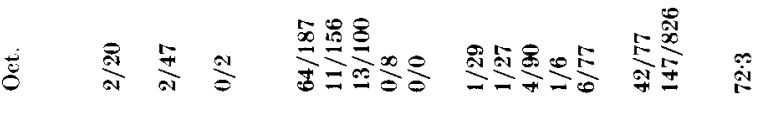

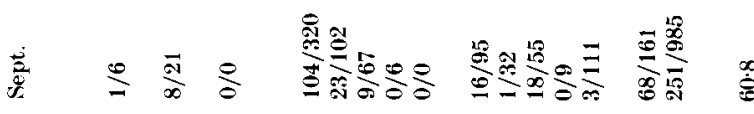

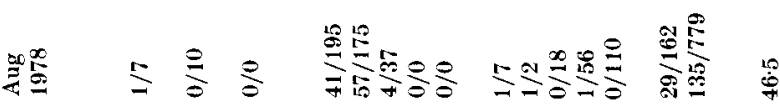

है

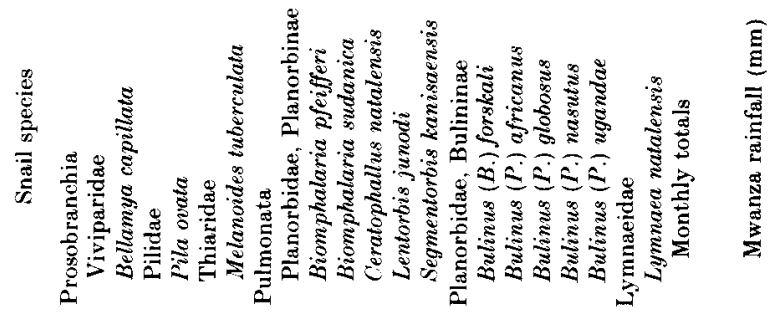




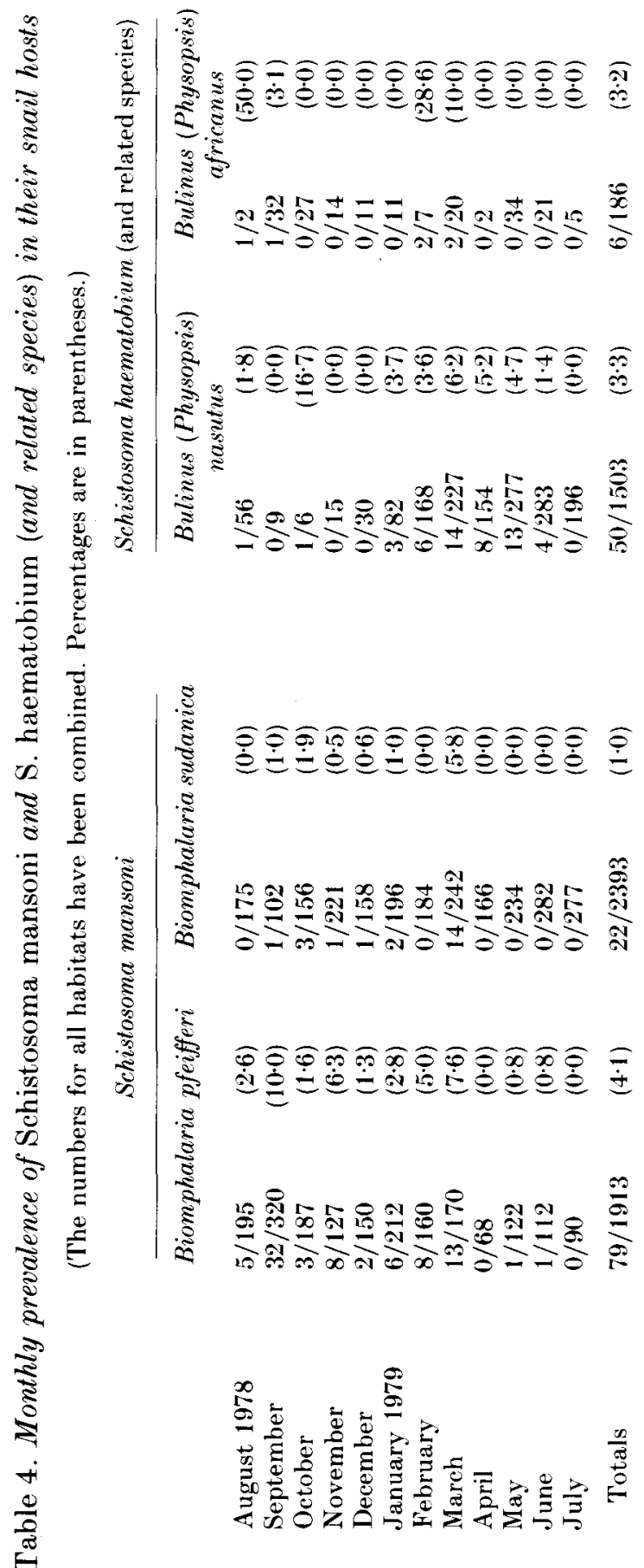


infection rates were highest from March to April. L. natalensis infection rates were consistently high throughout the 12-month observation period. One possible factor contributing to the high infection rates observed during the late dry-early rainy season is the reduced water volume observed in most habitats during this period; smaller water volumes accompanied by intensified use by definitive hosts would increase the probability of miracidium-snail contacts, other factors being equal.

The number of species of cercariae recovered was highest during September (22 species) and remained relatively high (between 15 and 20 species each month) through April, and began to decline sharply thereafter to a low of 10 species in July. This decline may be explained in part by a decrease in the relative proportion of $B$. pfeifferi, $C$. natalensis and $B$. (B.) forskali which were collected between May and July. These 3 host species all harboured a diverse trematode fauna; from January to March when diversity was high, these snails comprised $35.8 \%$ of all snails collected, whereas from May until the end of July they accounted for only $\mathbf{1 3 . 5} \%$ of the collected snails.

Cercariae identified as S. mansoni (Cercaria no. 1, Table 2) on the basis of general morphology and pattern of argentophilic papillae (Short \& Kuntz, 1976) were recovered from both $B$. sudanica and $B$. pfeifferi, with the latter host more than 4 times as likely to be infected. S. mansoni was one of 14 species of cercariae recovered from these 2 hosts. Five of 9 habitats yielded S. mansoni infections, all of which were in Mwanza.

Of the 5 species of bulinid snails collected, only 2 were found to carry infections of mammalian schistosomes (Cercaria no. 2, Table 2), with the majority being recovered from $B$. (P.) nasutus (Table 4). The schistosome commonly recovered from $B$. (P.) nasutus was probably $S$. haematobium since Kinoti $(1964 b)$ has demonstrated that a Mwanza strain of this snail host is refractory to local $S$. bovis and a Nelspruit strain of $S$. mattheei; Webbe (1962b) has clearly implicated this snail species as a major intermediate host for $S$. haematobium in the Mwanza region. The specific identity of the schistosome infections noted in $B$. (P.) africanus is unclear; this snail species is known to be susceptible to all 3 of the above terminal-spined egg schistosome species (Kinoti, 1964a,b). Of 64 trematode infections observed in $B$. (P.) nasutus and $B$. (P.) africanus, 56 were mammalian schistosome infections. Four habitats were found to harbour schistosome-infected bulinid snails, none of which was located in Mwanza town.

F. gigantica (Cercaria no. 31) was found sporadically until March and was then found every month until the study was completed. Most of the infections were reported from habitat $\mathrm{F}$ (18 of 25$)$. It was the third most common of 6 cercarial species recovered from $L$. natalensis.

Of 38 morphologically distinguishable types of cercariae, 22 were recovered from a single host species, 8 were obtained from 2 or more species of the same genus, 6 (nos, 7, 9, 16, 19, 25 and 33 ) were derived from snails of 2 different genera, and 2 (nos 28 and 34 ) were each recovered from 4 different genera of hosts. In the cases of Cercariae 7 and 9 , the limited material available for study did not permit extensive observation of all morphological details; further study of this material may have revealed specific differences in similar cercariae from different hosts. With respect to Cercariae 33 and 34 , due to the massive amounts of cystogenous material present in amphistome cercariae, much of the internal morphology was obscured and subtle differences could have easily been masked. 
Table 5. Recognizable double infections encountered in snails examined during this study

Parasite combination observed

Sporocyst-sporocyst

1 and $7 *$

1 and 16

14 and 16

14 and 16

Sporocyst-redia

1 and 25

14 and immature rediae

14 and 38

16 and immature rediae

16 and 30

16 and 38

16 and 38

36 and immature sporocysts

Total

No. of

times

Host

observed

* Numbers in this column refer to the cercaria numbers listed in Table 2.

The remaining 4 species reported from hosts belonging to 2 or more genera may represent true examples of non-specificity of a single trematode species with respect to the first intermediate host. For each of these 4 cercariae, the reported host species were all members of the Planorbidae, suggesting that their host specificity may exist at the familial rather than the generic or specific level. Particularly intriguing was Cercaria No. 28, an echinostome which was found in 4 genera and 6 species of snail hosts only from February to April. Collar spine and flame cell counts appeared to be constant in the specimens of this cercaria recovered from different habitats and snail hosts, but other more subtle differences may have been overlooked and for this cercaria, as well as the others, the existence of sibling species may only be detected by the appropriate life-cycle experiments. It should also be noted that Cercariae 36, 37 and 38 all resembled $C$. aequatorialis Fain very closely but were considered as separate species on the basis of size differences, host species and habitat distributions.

Infections involving the sporocysts and/or rediae of 2 different trematode species in a single host were discovered 21 times (Table 5). Approximately 1.2\% of all infected snails were found to contain such double infections, although the true prevalence of this condition was probably higher. No infections involving sporocysts and/or rediae of 3 different trematode species were noted.

\section{DISCUSSION}

With the exception of $S$. mansoni, $F$. gigantica and the mammalian schistosome recovered from bulinid snails, there was little similarity between the cercariae observed in this study and those reported by Porter (1938) from South African freshwater snails. Selected results of the present study are compared with those of Fain (1953) and Vercammen-Grandjean (1960) in Table 6. Fain (1953) examined 
Table 6. Comparison of results of Fain (1953) and Vercammen-Grandjean (1960) with present study

$\begin{array}{cccc}\text { Fain } & \begin{array}{c}\text { Vercammen- } \\ \text { Grandjean }\end{array} & \begin{array}{c}\text { Present } \\ \text { study }\end{array} & \begin{array}{c}\text { Integrated } \\ \text { totals }\end{array}\end{array}$

No. of snail species or

varieties examined

No. of snails examined

No. of snails infected $(\%)$

No. of species of

(1960)

study totals

25

27860

10

$1071^{*}(3 \cdot 8)$

Approx. 15000

2188* (14.6)

14
11708
$1748(14 \cdot 9)$

31

54568

$5007(9 \cdot 2)$

$371^{*}(6 \cdot 2)$
8 cercariae recovered

No. of species recovered

for the first time

Bulinus

No. examined

No. infected $(\%)$

No. of species recovered
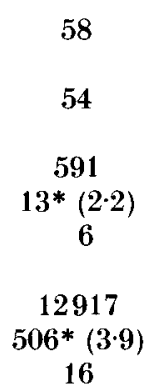

3371

$159 *(4 \cdot 7)$

6

34

32

386

$11^{*}(2 \cdot 8)$

3

No. examined

No. infected $(\%)$

No. of species recovered

Lymnaea

No. examined

No. infected $(\%)$

No. of species recovered

* These figures underestimate the true prevalence of infection because snails were only examined for shedding cercariae and were not dissected to reveal immature infections.

snails from in and around Lake Albert (with additional minor collections from Lake Kivu, Ruanda and Burundi), and 13 of the cercarial species reported by him were also noted in this study (Table 2). Many of the snails examined by Fain were prosobranchs from lacustrine habitats whereas few of the snails collected in the present study were prosobranchs and none was collected from lakes, otherwise the similarities in cercarial faunas of the two studies would have been even greater. For instance, one small collection made from Pasiansi Bay in Lake Victoria (Loker, unpublished observations) yielded 4 cercarial species from Melanoides tuberculata which closely corresponded to Fain's (1953) descriptions of $C$. dimorpha, $C$. dissimilis, C. laticaeca and C. sigmoida; also, one cercaria recovered from Gabbiella humerosa (= Bithynia alberti) closely resembled $C$. schoutedeni reported by Fain (1953) from Melanoides.

Of the 34 cercarial species recovered by Vercammen-Grandjean (1960) in snails from the Bukavu region of Lake Kivu, only 3 species were observed in the present study (Table 2). Thus, although Lake Kivu is closer to the Mwanza region than Lake Albert, the greater similarities observed in the cercarial fauna of the Mwanza region and Lake Albert may be a reflection of the fact that both locations are situated in the Nile drainage system, whereas Lake Kivu drains south into Lake Tanganyika.

The snail species in Fain's (1953) study which yielded the greatest number of cercarial species was $M$. tuberculata with 12 , and the highest prevalence of infection was reported in $B$. pfeifferi $(7 \cdot 1 \%)$. Vercammen-Grandjean (1960) found both the 
maximum prevalence of infection $(31.9 \%)$ and number of cercarial species $(9)$ in L. natalensis. The overall prevalence rates reported by these two authors apparently do not include immature sporocyst or redia infections, which leads to substantial underestimation of the true infection rate $(22 \cdot 2 \%$ of all infections recorded in the present study fell into this category).

Of all trematode infections in Biomphalaria reported by Fain, $31.0 \%$ were $S$. mansoni and $29.6 \%$ were $C$. blukwa ; the corresponding figures for the present study were $13 \cdot 2 \%$ and $40.0 \%$ respectively.

Mammalian schistosome cercariae from bulinid snails were not reported by either Fain (1953) or Vercammen-Grandjean (1960); in the present study they comprised $30 \cdot 2 \%$ of all trematode infections from these hosts. Mammalian schistosomes were by far the most common type of cercaria recovered from $B$. $(P$.) africanus and $B$. (P.) nasutus.

$F$. gigantica accounted for 87 of 97 recognizable infections recovered from lymnaeid snails by Fain (1953), whereas in the present study only $3.9 \%$ of 645 infections from L. natalensis were of this species. C. guttera infections were found in only 3 snails by Fain (1953) but in the present study this species was very common, accounting for $55.3 \%$ of all infections from $L$. natalensis. The actual prevalence of this xiphidiocercaria in the present study was almost certainly higher, due to the large number of immature sporocyst infections that were recorded for $L$. natalensis.

The high infection rates of the xiphidiocercariae $C$.guttera in L. natalensis and C. blukwa in Biomphalaria here reported invite speculation that they may exert some influence on the prevalence of $F$. gigantica and $S$. mansoni infections respectively. $C$. guttera was 14 times more common than $F$. gigantica in $L$. natalensis, and $F$. gigantica was most commonly recovered from habitat $F$ where C. guttera was absent. In the two habitats where $C$. guttera was most common (B and E), F. gigantica was absent. However, 4 of the $25 F$. gigantica infections noted were reported from habitats where $C$. guttera was also found.

The ability of $C$.guttera (which is produced in sporocysts) to serve as an effective intramolluscan antagonist to prevent establishment of, or to displace $F$. gigantica rediae is not known. No double infections involving $C$. guttera were noted, which may imply that this species is an effective competitor. It was frequently observed that the largest specimens of $L$. natalensis collected were infected with this trematode, and that the survival of these snails in the laboratory was very poor. Although C. guttera is obviously not exerting an absolute suppressive effect and $F$. gigantica is widespread in the Mwanza region, interspecific trematode competition for intermediate hosts may be exerting some measure of 'natural biological control' similar to the postulated negative effects exerted by echinostomes on the infection rates of Bulinus truncatus with S. haematobium in Egypt (Chu et al. 1972).

C. blukwa was 3 times more common in Biomphalaria than S. mansoni; of the 5 habitats in which $S$. mansoni was found, C. blukwa was present in 4 and abundant in 3 . The 2 habitats most consistently yielding $S$. mansoni infections (B and D) yielded the greatest number of $C$. blukwa infections. C. blukwa was found in 16 of the 21 double infections reported in this study, including 4 with $S$. mansoni. Interestingly, of 42 double infections reported by Fain (1953), 34 apparently 
involved C. blukwa and S. mansoni. The orange sporocysts of C. blukwa which were easily seen through the shell of infected Biomphalaria were typically located in the region occupied by the albumen gland, leaving the digestive gland largely unoccupied, a factor which may have contributed to the large number of double infections involving this species. Further study of the role these xiphidiocercariae play in modifying the prevalence of schistosomiasis and fascioliasis is needed, especially considering the observations of Bourns (1963) and Wright (1966) which suggested that infections with xiphidiocercariae may predispose snails to infections with other trematodes or vice versa.

In contrast, Paperna (1967) noted that Bulinus truncatus rohlfsi previously infected with xiphidiocercariae were considerably less likely to develop patent $S$. haematobium infections than were control snails not infected with xiphidiocercariae.

Of all trematode infections recovered in Bulinus, $40 \%$ were redial infections and of these, the most common was $C$. aequatorialis (no. 35), a cystophorous cercaria which accounted for $27.0 \%$ of all infections in this host genus. Approximately $20 \%$ of all infected Biomphalaria contained redial infection. The cercarial species originating from rediae which were most commonly recovered from Biomphalaria were C. lileta (no. 20) and the cystophorous cercaria, C. bulla (no. 38). All 3 of these parasite species are apparently widespread as they were also recovered by Fain (1953). C. lileta closely resembles the cercariae of described species of the genus Ribeiroia (see Yamaguti, 1975). R. marini guadeloupensis has been shown to attain a very high prevalence in natural populations of $B$. glabrata in Guadeloupe (Pointier, Salvat, Deplanque \& Golvan, 1977), and it is known to effectively castrate this snail host (Golvan, Combes, Bayssade-Dufour \& Nassi, 1974). These attributes have led to field trials to investigate its efficacy as a biological control agent of B. glabrata in the Neotropics (Nassi et al. 1979).

Cercariae of Echinoparyphium recurvatum and Echinostoma revolutum which have been frequently reported from schistosome intermediate hosts in other parts of Africa (Bisseru, 1967 ; Moravec, Barus, Rysavy \& Yousif, 1974; Wright, Rollinson $\&$ Goll, 1979) were not found in the 9 habitats studied.

Prevalence of infection and diversity of the trematode fauna were found to vary considerably between hosts and habitats and with season. As noted by Wright $e t$ al. (1979), such variability serves 'to emphasize the dangers of drawing conclusions concerning the host-capacity of a snail species from isolated samples'.

The highly seasonal nature of schistosome transmission in $B$. $(P$.) nasutus reported by Webbe $(1962 b)$ was noted in habitats $\mathrm{F}$ and $\mathrm{G}$. Very few $B$. (P.) nasutus were collected from these 2 habitats during the late dry season of 1978 , but when the rainy season began, these snails became more numerous and from February to the end of the study in July they were very abundant. Schistosome infections were recovered from these habitats from January to June (Table 4), with the highest monthly prevalence recorded in March $(7.5 \%)$, somewhat earlier than the peak infection rates in June, July and August (3-13\%) in the more extensive collections of this species reported by Webbe $(1962 b)$. Of $17293 B$. (P.) nasutus collected by Webbe $(1962 b)$ in 20 temporary ponds south of Mwanza, $739(4 \cdot 3 \%)$ were shedding $S$. haematobium cercariae. McCullough et al. (1968) recovered $B$. (P.) nasutus from 176 of 362 habitats in the Misungwi area but found schistosome-infected snails in 
only 8 of the habitats; out of $6172 B$. (P.) nasutus collected by these workers, only $23(0 \cdot 3 \%)$ shed mammalian schistosome cercariae.

In previous studies of $S$. mansoni transmission in urban Mwanza, Webbe (1962a) and McCullough et al. (1972) have observed that $S$. mansoni infections from $B$. sudanica and $B$. pfeifferi can be recovered throughout the year and that infection rates fluctuated considerably. In the present study, S. mansoni infection rates were observed to fluctuate, but a substantial overall decline in the infection rate was noted during the last 3 months of observation ('Table 4).

The recovery of S. mansoni-infected Biomphalaria only from urban Mwanza, and of schistosome-infected bulinid snails only from rural areas conforms with earlier extensive observations on the transmission of schistosomiasis in the Mwanza region (summarized by McCullough \& Eyakuze (1973)). This distinction is certainly not absolute, and although no $S$. mansoni infections were found in Biomphalaria examined from rural areas, low-level $S$. mansoni transmission is known to occur in the Misungwi area (McCullough \& Eyakuze 1973). Likewise, in Mwanza no natural schistosome infections were found in several bulinid snails of the sub-genus Physopsis (including several collected in habitats frequented by children), but $B$. $(P$.) globosus from Kirumba Stream has on one occasion been previously found to shed S. haematobium cercariae (McCullough et al. 1972). It is perhaps noteworthy that laboratory-reared progeny of bulinid snails originating from Kitangiri Stream (habitat D) and tentatively identified as $B$. $(P$.$) globosus were found to be$ susceptible to the local strain of S. haematobium.

Much additional study is needed to elucidate the biocontrol potential of many of the trematode species here reported, and of other as yet undiscovered species, in their African snail hosts. The magnitude of the competitive effects exerted by these species against trematodes of medical or veterinary significance may be greater than realized if, as suggested by Basch (1975), snail populations are heterogeneous with respect to their susceptibility to trematode infection. Thus, although at any given time the proportion of hosts infected within a particular population is low, the proportion of susceptible snails that is infected may be quite high. If the determinants of susceptibility are the same or similar for two species of trematode species utilizing the same host population, interspecific competitive interactions may be much more intense than the overall infection rates for the entire host population might suggest. The admirable theoretical approach taken by Anderson \& May (1979) to predict the prevalence of schistosome infection within molluscan populations can perhaps be modified to include consideration of other trematodes utilizing the same host population. An understanding of the magnitude of these potential competitive effects would be relevant to future control programs.

The authors thank the Tanzanian Scientific Research Council for permission to undertake this study. The full cooperation of Director Dr W. K. Rutasitara and the staff of the Institute for Medical Research in Mwanza, Tanzania is gratefully acknowledged. Dr David S. Brown of the Experimental Taxonomy Unit, Zoology Department, British Museum (Natural History) identified many of the snail hosts and provided valuable suggestions regarding their classification. Dr David Matovu also contributed valuable comments regarding snail taxonomy. Dr Alex Fain, Dr Christopher J. Bayne, Dr Fergus McCullough and Dr Brown all read the manuseript and provided helpful comments. The authors thank Ms Suzi Sargent for excellent secretarial assistance. The study was supported by a Fulbright-Hays full grant to the senior author. 


\section{REFER E N C ES}

Anderson, R. M. \& MAY, R. M. (1979). Prevalence of schistosome infections within molluscan populations: observed patterns and theoretical predictions. Parasitology 79, 63-94.

BaAlawy, S. S. \& Moyo, H. G. (1970). Studies on the population dynamics of $B$. (P.) nasutus and natural $S$. haematobium infection rates in relation to rainfall at Misungwi and Usagara, Mwanza. East African Medical Journal 47, 472-8.

BASCH, P. F. (1975). An interpretation of snail-trematode infection rates: specificity based on concordance of compatible phenotypes. International Journal for Parasitology 5, 449-52.

Berrie, A. D. (1964). Observations on the life-cycle of Bulinus (Physopsis) ugandae MandahlBarth, its ecological relation to Biomphalaria sudanica tanganyicensis (Smith), and its role as an intermediate host of Schistosoma. Annals of Tropical Medicine and Parasitology 58, 457-66.

BISSERU, B. (1967). Stages in the development of larval echinostomes recovered from schistosome transmitting molluses in Central Africa. Journal of Helminthology 41, 89-108.

BourNs, T. K. R. (1963). Larval trematodes parasitizing Lymnaea stagnalis appressa Say in Ontario with emphasis on multiple infections. Canadian Journal of Zoology 41, 937-41.

ChU, K. Y., Dawood, I. K. \& NABI, H. A. (1972). Seasonal abundance of trematode cercariae in Bulinus truncatus in a small focus of schistosomiasis in the Nile Delta. Bulletin of the World Health Organization 47, 420-2.

Cridland, C. C. $(1957 a)$. Ecological factors affecting the numbers of snails in permanent bodies of water. Journal of Tropical Medicine and Hygiene 60, 250-6.

Cridland, C. C. $(1957 b)$. Ecological factors affecting the numbers of snails in temporary bodies of water. Journal of Tropical Medicine and Hygiene 60, 287-93.

Criduand C. C. (1958). Ecological factors affecting the numbers of snails in a permanent stream. Journal of Tropical Medicine and Hygiene 61, 16-20.

Dinnik, J. A. \& Dinnik, N. N. (1965). The schistosomes of domestic ruminants in Eastern Africa. Bulletin of Epizootic Diseases of Africa 13, 341-59.

FAIN, A. (1953). Contribution à l'étude des formes larvaires des Trématodes au Congo belge et spécialement de la larve de Schistosoma mansoni. Mémoires, Institut Royal Colonial Belge. Section des Sciences Naturelles et Medicales 22, 1-312.

Golvan, Y..J., Combes, C., Bayssade-Dufour, C. \& Nassi, H. (1974). Les cercaires de Ribeiroia marini (Faust et Hoffman, 1934). Trématode antagoniste de Schistosoma mansoni et provoquant la castration du Mollusque-hôte, vecteur de la Bilharziose humaine. Comptes rendus Académie des sciences, Paris 279, 405-8.

KINOTI, G. (1964a). Observations on the transmission of Schistosoma haematobium and Schistosoma bovis in the lake region of Tanganyika. Bulletin of the World Health Organization 31, 815-23.

Kinoti, G. (1964b). A note on the susceptibility of some gastropod molluses to Schistosoma bovis and S. mattheei. Annals of Tropical Medicine and Parasitology 58, 270-5.

Lie, K. J., Kwo, E. H. \& Owyang, C. K. (1971). Further field trial to control Schistosoma spindale by trematode antagonism. Southeast Asian Journal of Tropical Medicine and Public Health 2, 237-43.

Lie, K. J., Schneider, C. R., Sornmani, S., Lanza, G. R. \& Impand, P. (1974). Biological control by trematode antagonism. I. A successful field trial to control Schistosoma spindale in northeastern Thailand. Southeast Asian Journal of Tropical Medicine and Public Health $\mathbf{5}$, $46-59$.

Maclean, G., Webbe, G. \& Msangi, A. S. (1958). A report on the bilharzia and molluscan survey in the Tanga district of Tanganyika. East African Medical Journal 35, 7-22.

Magendantz, M. (1972). The biology of Biomphalaria choanomphala and B. sudanica in relation to their role in the transmission of Schistosoma mansoni in Lake Victoria at Mwanza, Tanzania. Bulletin of the World Health Organization 47, 331-42.

McCullough, F.S. (1981). Biological control of the snail intermediate hosts of human Schistosoma spp.: a review of its present status and future prospects. Acta Tropica 38, 5-14.

McCullough F. \& Eyakuze, V. M. (1973). WHO/Tanzania schistosomiasis pilot control and training project. Mwanza district, Tanzania-Final Report. World Health Organization Regional Office for Africa AFR/SCHIST/29.

McCullovgh, F. S., Eyakuze, V. M., Msinde, J. \& Noiti, H. (1968). Water resources and bilharziasis transmission in the Misungwi area, Mwanza district, northwest Tanzania. East Africa Medical Journal 45, 295-308. 
McCullough, F. S., Webbe, G., BaAlawy, S. S. \& Maselle, S. (1972). An analysis of factors influencing the epidemiology and control of human schistosome infections in Mwanza, Tanzania. East African Medical Journal 49, 568-82.

Moravec, F., Barus, V., Rysavy, B. \& Yousif, F. (1974). Observations on the development of two echinostomes, Echinoparyphium recurvatum and Echinostoma revolutum, the antagonists of human schistosomes in Egypt. Folia Parasitologica (Praha) 21, 107-26.

MorRis, J. R. (1970). An ecological study of the basommatophoran snail Helisoma trivolvis in central Alberta. Ph.D. thesis, University of Alberta.

Nassi, H., Pointier, J.-P. \& Golvan, Y.-J. (1979). Bilan d'un essai de contrôle de Biomphalaria glabrata en Guadeloupe à l'aide d'un trématode stérilisant. Annales de Parasitologie (Paris) 54, $185-92$.

Ogambo-Ongoma, A. H. (1971). Field epidemiology of fascioliasis in Port Bell, Uganda. Bulletin of Epizootic Diseases of Africa 19, 341-51.

Paperna, I. (1967). The effect of pre-existing trematode infection on the establishment of Schistosoma haematobium larvae in bulinid snails. Ghana Medical Journal 6, 89-90.

Pointier, J. P., Salvat, B., Delplanque, A. \& Golvan, Y. (1977). Principaux facteurs régissant la densité des populations de Biomphalaria glabrata (Say 1818), mollusque vecteur de la Schistosomose en Guadeloupe (Antilles françaises). Annales de Parasitologie Humaine et Comparee 52, 277-323.,

Port fr, A. (1938). The larval Trematoda found in certain South African Mollusca with special reference to schistosomiasis (bilharziasis). Publication of the South African Institute for Medical Research 8, 1-492.

Pren'tice, M. A., Panesar, T. S. \& Coles, G. C. (1970). Transmission of Schistosoma mansoni in a large body of water. Annals of Tropical Medicine and Parasitology 64, 339-48.

Rolinson, D. \& Southgate, V. R. (1979). Enzyme analyses of Bulinus africanus group snails (Mollusca: Planorbidae) from Tanzania. Transactions of the Royal Society of Tropical Medicine and Hygiene 73, 667-72.

Short, R. B. \& Kuntz, R. E. (1976). Patterns of argentophilic papillae of Schistosoma rodhaini and S. mansoni cercariae. Journal of Parasitology 62, 420-5.

TeEsdale, C. (1962). Ecological observations on the molluses of significance in the transmission of bilharziasis in Kenya. Bulletin of the World Health Organization 27, 759-82.

Vercammen-Grandjean, P. H. (1960). Les trématodes du Lac Kivu Sud. Musee Royal de l'Afrique Centrale, Tervuren, Belgique - Annales-Nouvelle Serie in $4^{\circ}$-Sciences Zoologiques $\mathbf{5}$, $1-171$.

Webre, G. (1962a). Population studies of intermediate hosts in relation to transmission of bilharziasis in East Africa. In Ciba Foundation Symposium on Bilharziasis, (ed. G. E. W. Wolstenholme and M. O'Connor), pp. 7-22. Boston: Little, Brown and Company.

WeBbe, G. $(1962 b)$. The transmission of Schistosoma haematobium in an area of Lake Province, Tanganyika. Bulletin of the World Health Organization 27, 59-85.

WebBe, G. \& Msangi, A.S. (1958). Observations on three species of Bulinus on the East Coast of Africa. Annals of Tropical Medicine and Parasitology 52, 302-14.

Wesen Berg-Lund, C. (1934). Contributions to the development of the Trematoda Digenea. Part II. The biology of the freshwater cercariae in Danish freshwaters. Mémoires de l'Académie Royale des Sciences et des Lettres de Danemark, Copenhague. Section des Sciences, 9 série 5(3), 1220.

Wright, C. A. (1966). The pathogenesis of helminths in the Mollusca. Helminthological Abstracts 35, 207-24.

Wright, C. A., Rollinson, D. \& Goll, P. H. (1979). Parasites in Bulinus senegalensis (Mollusca: Planorbidae) and their detection. Parasitology 79, 95-105.

Yamaguti, S. (1975). A Synoptical Review of Life Histories of Digenetic Trematodes of Vertebrates. Kyoto, Japan. 